Entscheidung "eine notwendige, jedoch keine hinreichende Bedingung der Völkerrechtsgemäßheit einer territorialen Veränderung, insbesondere einer Sezession" sei (S. 474). Sogar die Einordnung als erga omnes-Verpflichtung sei "sinnvoll" (S. 476). Für die Rechtsfolgen einer Verletzung des Abstimmungserfordernisses nimmt die Verfasserin die zutreffende Unterscheidung zwischen völkerrechtlicher Rechtswidrigkeit und Nichtigkeit vor und befürwortet nach dem Vorbild der sog. Stimson-Doktrin eine Nichtanerkennungspflicht dritter Staaten (S. 481-486).

Insgesamt handelt es sich um eine Untersuchung mit zwei auch in ihrer dogmatischen Stringenz sehr unterschiedlichen Teilen. Der induktive Haupteil bringt eine detaillierte und anschauliche Aufarbeitung des relevanten Praxismaterials und ist als solcher von bleibendem wissenschaftlichen Wert. Der Blick für eine nüchterne Wertung dieser Staatenpraxis scheint der Verfasserin allerdings durch ihr dogmatisches Vorverständnis verstellt zu sein. Dieses zeigt sich im "deduktiven" Hauptteil, der aus abstrakten Prinzipien mit rechtspolitischen Erwägungen eine bindende völkerrechtliche Verfahrensnorm ableitet, die mit den Strukturen des geltenden Völkerrechts nur schwer zu vereinbaren ist. Wie sehr dies Ergebnis zudem an den Realitäten der Staatenpraxis vorbeigeht, zeigt nicht zuletzt die jüngst erzielte Friedensregelung für Bosnien-Herzegowina, durch die mit Billigung der gesamten Staatengemeinschaft (universelle Rechtsüberzeugung!) erhebliche territoriale Neugliederungen vorgenommen wurden, ohne daß jemand nach dem Willen der betroffenen Bevölkerung gefragt hätte.

Oliver Dörr

\title{
Mohamed Munavvar
}

Ocean State - Archipelagic Regimes in the Law of the Sea

Publications on Ocean Development, Vol. 22

Martinus Nijhoff Publishers, Dordrecht, 1995, 225 S., $£ 74.00$

Zu den neuen Konzepten des UN-Seerechtsübereinkommens (SRÜ) von 1982 (bisher für 81 Staaten in Kraft getreten) zählen neben der 200 Seemeilen-Wirtschaftszone, dem Tiefsee-Regime und der Streitregelung auch das Archipel-Konzept, dem diese Monographie gewidmet ist.

Munavver unterscheidet drei Typen von Archipelen: erstens "Küstenarchipele", d.h. Inselketten oder -gruppen vor einer Festlandsküste (z.B norwegische Schären), zweitens "Ozeanische Archipele" von Küstenstaaten (z.B.Galapagos/Equador) und drittens "Archipelstaaten"(wie Indonesien oder Fiji), also Staaten, die vollständig aus Inseln bestehen.

Die Kapitel 1 bis 3 dokumentieren die völkerrechtliche Entwicklung dieser archipelagischen Regime anhand der neueren Seerechtsentwicklung, wobei das Konzept der "Archipelstaaten" und seine Umsetzung in einem eigenen Abschnitt IV des SRÜ in den Artikeln 
46 bis 54 im Vordergrund stehen. Während die erstgenannten Typen von Archipelen sich allenfalls als Spezialfälle von Basislinien zur maritimen Grenzfindung im Seerecht nachweisen lassen, sind die Archipelstaaten deutlich privilegiert: Mit Hilfe extrem langer "archipelagischer Basislinien" von über 100 Seemeilen Länge können die Gewässer zwischen den Inseln der Archipelstaaten der nationalen Souveränität unterstellt werden, um so die Einheit von Land und Meer, von Ressourcen und Menschen und damit die Identität dieser Inselstaaten zu stärken.

Das virtuose Instrumentarium zur großzügigen Grenzziehung wird in Kapital 3 ausführlich und korrekt dargestellt. Diesem besonders informativen Abschnitt der archipelagischen Sonderrechte folgen - vergleichsweise etwas knapper - die verbleibenden Nutzungsrechte der Staatengemeinschaft wie z.B. die archipelagischen Durchfahrtsrechte (ähnlich dem Meerengenrecht), aber auch Luftverkehrs- und Kabelrechte sowie die Fischerei-Interessen der Nachbarstaaten.

Ein weiteres Mal wird deutlich, daß das SRÜ tatsächlich ein breit angelegter, mehr oder weniger ausgewogener Interessenausgleich zwischen den Nationalisierungsbestrebungen der Küsten- und Inselstaaten einerseits und den Verkehrs-, Kommunikations- und Sicherheitsinteressen der seefahrenden Staaten andererseits ist.

Der Verfasser dieses Buches ist selbst nichts frei von diesem Konflikt, wenn er begrifflich großzügig die Archipelgewässer gelegentlich (S. 175, 186) ausdrücklich mit "territory" gleichsetzt (mal mit und mal ohne Anführungszeichen). Zum Glück beschreibt er an anderer Stelle (S. 5 und 155) die Archipelgewässer zutreffend als Gewässer "sui generis", die keineswegs einer völligen Nationalisierung anheimfallen. Vorsicht ist ebenfalls geboten, wenn der Verfasser am Ende des Buches ohne weitere Güterabwägung für eine Übertragung des Archipelstaaten-Konzepts auf andere Archipele eintritt und zusätzlich eine Beschränkung der Durchfahrtsrechte fremder Schiffe fordert.

Trotz dieser kritischen Anmerkungen ist das Werk von Munavver wichtig, da es die legitimen Interessen der Archipelstaaten und ihren großen Erfolg auf der UN-Seerechtskonferenz sachkundig und engagiert aufgearbeitet hat. Soweit hier bekannt, ist es die erste umfassende Darstellung zu diesem Thema.

Uwe Jenisch

Michael Traßl

Die Wiedergutmachung von Menschenrechtsverletzungen im Völkerrecht

Schriften zum Völkerrecht, Bd. 111

Duncker \& Humblot, Berlin, 1994, 148 S., DM 68,--

Das klassische Völkerrecht war ein Recht zwischen Staaten. Der einzelne wurde durch seine Normen nicht berechtigt, sondern allenfalls mittelbar begünstigt, so durch das völker- 